\title{
Hydrological Modelling of Bina River Basin in Madhya Pradesh, India
}

\author{
HL Tiwari ${ }^{1}$ and Ankit Balvanshi ${ }^{2 *}$ \\ ${ }^{1}$ Associate Professor, Department of Civil Engineering, Maulana Azad National Institute of Technology, Bhopal, India \\ ${ }^{2}$ Research Scholar, Department of Civil Engineering, Maulana Azad National Institute of Technology, Bhopal, India
}

*Corresponding author: Ankit Balvanshi, Research Scholar, Department of Civil

Engineering, Maulana Azad National Institute of Technology, Bhopal, 462007, India.

Received Date: August 03, 2020

Published Date: August 28, 2020

\begin{abstract}
Rainfall-runoff models have been widely used through the last century all over the world. These models help to build a trustworthy relationship between the precipitation and runoff. The relationship between rainfall and runoff is essential in a catchment for hydrologic analysis and design. In the current paper, our main objective is to compute runoff by employing two hydrological models namely SCS CN and RRL toolkit Australian Water Balance Model (AWBM) and to check the which model is more suitable for runoff estimation in the Bina basin. The SCS CN method is an empirical approach for estimation of Direct Runoff. The SCS CN method is highly trusted method and used by the hydrologists all over the globe for prediction of runoff. With SCS CN model, Arc Map 10.2 GIS tool is used to generate the soil map, the land use map and ultimately the composite curve number of the watershed is calculated. In the second model, RRL toolkit software is used in which the AWBM is selected for assessing the runoff. The AWBM is a catchment water balance model that relates runoff to rainfall with daily or hourly data. The daily rainfall data, and daily evapotranspiration data was given as input for the AWBM RRL toolkit. In total 5 years of daily data (1990-94), first 3 years of data was taken for model calibration and the rest 2 years data was taken for model validation. The coefficient of determination for the models was obtained indicating good agreement between the observed and simulated runoff. The models were also evaluated based on Nash-Sutcliffe Efficiency Index (EI). The Nash Sutcliffe efficiency obtained for calibration and validation of AWBM was found to be 0.852 and 0.890 respectively.
\end{abstract}

Keywords: SCS CN; RRL; AWBM; Evapotranspiration; Nash-Sutcliffe efficiency

\section{Introduction}

Water is the natural important resource which needs preservation, control and management. The water resources can be managed by implementing and improving the engineering practices. Practices include excess runoff diversion to agriculture land or to check dams so that runoff water is utilized. This management can only be done if rainfall and runoff study have been executed in that area. The hydrological behavior of the any watershed is to be taken care of for the effective planning of the water resources available. A rainfall-runoff model is a mathematical model that describes catchment and gives relationship between precipitation and runoff. A rainfall runoff model is helpful in computation of discharge from a basin. In most of the locations, the rainfall data is handy but the discharge or the runoff data is not available or is available in gaps. Modelling gives information to hold up the decision making of water management policies.

The proper planning and management of the water resources in a location becomes a real big trouble for the hydrologists if discharge data is not available. Hence, engineers and hydrologists from all over the world have inclined towards the computer software's for the estimation of runoff in any catchment or basin for handling any civil engineering project. These software models are more accurate and less time consuming than the physical method for the collection of data. They also have an advantage of extending the result and therefore future prediction is also possible. 
In the present study, Bina basin, Madhya Pradesh, India is chosen for rainfall runoff modelling. For this study area, two hydrological models namely the SCS CN model and the AWBM RRL model are developed and applied. As the Bina city is well known because of the industrial activities going on over here and runoff estimation is very much necessary therefore this basin is selected having Rahatgarh as the $\mathrm{g} / \mathrm{d}$ site.

\section{Review of Literature}

\section{SCS CN}

Reddy [1] worked to find the effect of land use on transportation network by employing the remote sensing techniques. In this study he used remote sensing data and found that these remote sensing data are more accurate and can be collected whenever required. Reddy [1] worked on the improvement of image classifier for land-use and land cover. He found that described that integrated information is provided by the remote sensing satellites. Yu [2] took assumptions as the spatial variability of infiltration capacities and the temporal variability in rainfall intensities. He came up with a SCS CN model based on the mentioned assumptions. He said that whenever the time varying rainfall rate surpasses the spatially variable, runoff will be produced. Mishra \& Singh [3] also did their research in this field. In the study the two hydrologists came up with the result that the SCS-CN equation can be developed from the water balance equation. But they used an assumption that rate of change of retention with effective precipitation is a linear function of retention. Nagarajan et al. [4] employed the SCS CN model in his study to find the impact of land use changes on surface runoff. He took a rural watershed of Tamil Nadu in this study. The result obtained implies that which month has more runoff and which month has lesser.

\section{AWBM}

Boughton [5] developed an AWBM model for the hydrologic rainfall runoff modelling. A set of 99 rainfall-runoff data sets of poor quality are used to test some methods. These rainfall runoff data were previously rejected. He concluded that this model gave more than two-third good calibrated values and scope of improvement of the data sets is present for further study. Haque Et al. [6] used the AWBM model for quantitative assessment of uncertainty. Both gauged and ungauged catchments were taken in the study. The main result obtained from this research work was that AWBM modeling outputs could vary from $-1.3 \%$ to $70 \%$ with two different input rainfall data. The performance of the AWBM model was found to be dominated mainly by the selection of appropriate rainfall data followed by the selection of an appropriate calibration data length and optimization algorithm. Yu [7] used two models for rainfall runoff computation namely AWBM and SimHyd for river Rambeod, French Alps. The Nash Sutcliffe efficiency for both AWBM and SimHyd models was around 0.71. Balvanshi \& Tiwari [8] developed a Rainfall Runoff model using AWBM for runoff estimation.
The coefficient of determinations for the model calibration and validation were 0.909 and 0.835 respectively. The model was also tested on Nash-Sutcliffe Efficiency Index (EI) and the calibration and validation values obtained were 0.824 and 0.618 respectively.

\section{Integration of GIS tool with the SCS CN and AWBM models}

Pradhan et al [9] used the remote sensing data and GIS tool to compute the rainfall runoff in Teesta river, east Singtam, Sikkim. The study was conducted for the year 2009. They believed that the conventional method of data collection is not accurate, so they used RS data and GIS tool. They found that this RS data is very useful in the rainfall runoff modelling and modelling can be done in remote areas also. Somashekar et al. [10] used the SCS CN method in their study on Hesaraghatta watershed. This research was conducted to obtain the runoff, They used the RS data in research. The IRS LISS III images in the form of False Colour Composites were used. They also concluded that the SCS method gives good results when accompanied with GIS and remote sensing data. Latha [11] developed SCS CN and Strange table models for Veernam tank, Tamil Nadu. The location of the catchment is latitude $11^{\circ} 15^{\prime} 00^{\prime \prime}$ and longitude $79^{\circ} 30^{\prime} 00^{\prime} \mathrm{E}$ in Cuddalore District of Tamil Nadu, India. The data used was of the period from 2000 to 2004. The analysis showed that SCS CN when used with GIS tool gives more accurate results. Dhawale [12] worked on Darewadi watershed of Maharashtra. In this study, he used the remote sensing data along with GIS tool for the computation of runoff. He employed the SCS $\mathrm{CN}$ method for the runoff estimation. He got 85 and 75 as curve number values using GIS tool. He concluded that the SCS CN method computes more precise surface runoff when RS and GIS tool is employed together. Kumar [13] developed two hydrological models named the SCS CN model and AWBM model in Tadepalli, Andhra Pradesh. The total catchment area was $61.5 \mathrm{sq} \mathrm{km}$. Along with SCS CN, GIS was used for obtaining the composite curve number and getting the land use/ land cover pattern. The value of corelation $\mathrm{r} 2=0.76$ was obtained between observed and computed runoff. Viji et al. [14] developed a SCS CN model using GIS tool for estimation of runoff in Kundahpalam Watershed, Nilgries District, Tamilnadu. The land use and composite CN $(48,68,83)$ were found and the runoff was estimated. The estimated runoffs were found comparable to the observed data. Joycee \& Santhi [15] used the CN method with GIS and remote sensing data for the estimation of runoff in the sub basin of Kodayar, Tamilnadu. The weighted curve number was found to be 75 . The runoff computed by the NRCS CN technique obtained a very good $\mathrm{R}^{2}$ value of 0.9939 .

\section{Materials and Methods}

\section{Study area}

Bina river begins from Raisen district near Bhopal, Madhya Pradesh. The river navigates across Rahatgarh and passes through Khurai and Bina tehsils of Sagar district. The Bina river meets the Betwa near Khurwai. The Bina Basin has coordinates extending 
from 23.55407 North and 78.290580 East to 24.171972 North and 78.038877 East. In its path the river Bina passes through Rahatgarh,
Eran, Bina, Belai, Jaisnagar and Begumganj. The total catchment area is $1180 \mathrm{~km}^{2}$ with the $\mathrm{g} / \mathrm{d}$ site located at Rahatgarh (Picture 1).

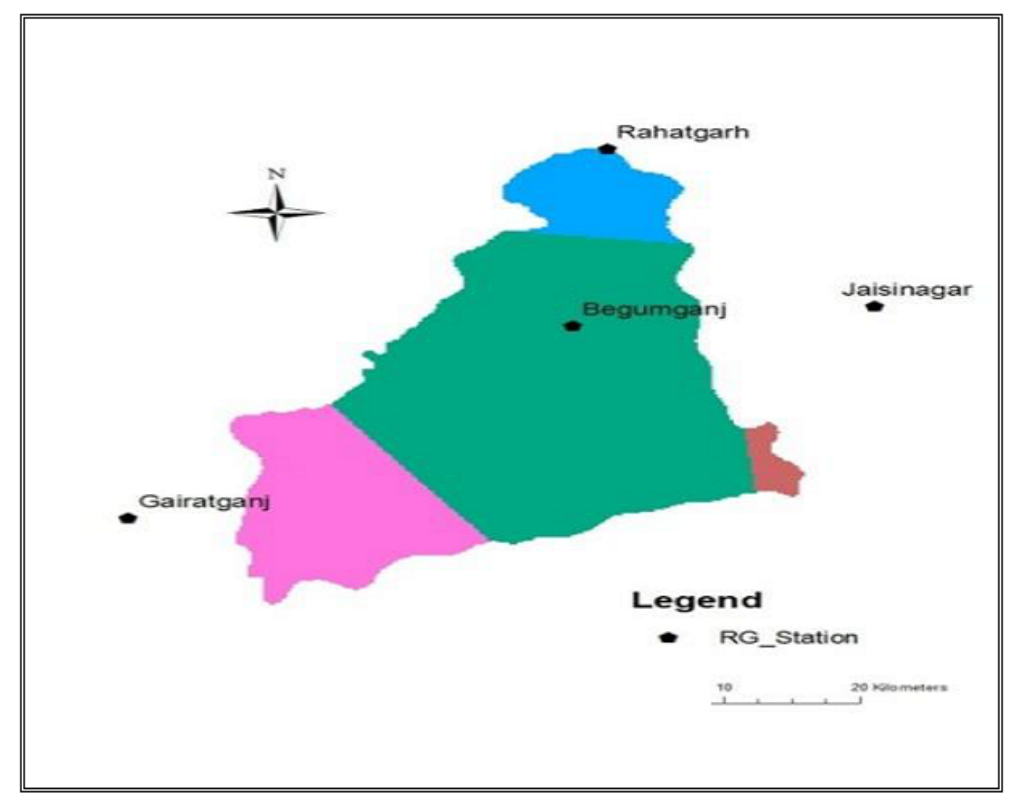

Figure 1: Theissen Map.

\section{SCS CN model}

In 1933, the Soil Erosion Service was set up in United States. The main objective of SES was to perform experiments and produce new measures for soil conservation. In 1935, a law known as the "soil conservation act of 1935" changed the agency name to Soil
Conservation Service. Later on, in 1994, the name was again changed from soil conservation service to NRCS (Natural Resources Conservation Service). Our purpose is to estimate the runoff of the Bina basin, using the curve number obtained using GIS tool and substituting it in the model (Picture 2). 


$$
P=Q+F+I_{a}
$$

This is Water Balance Equation.

$$
\frac{F}{S}=\frac{Q}{P-I_{a}}
$$

This is proportionality equality hypothesis.

From eqs. (i) \& (ii),

$$
\begin{gathered}
\frac{P-I_{a}-Q}{S}=\frac{Q}{P-I_{a}} \\
\mathrm{Q}=\frac{\left(P-I_{a}\right)^{2}}{\left(P-I_{a}\right)+S} \\
\mathrm{Q}=\frac{(P-0.2 S)^{2}}{(P+0.8 S)}, \quad\left(\mathrm{I}_{\mathrm{a}}=0.2 \mathrm{~S}\right) \\
\mathrm{S}=\frac{25400}{C N}-254
\end{gathered}
$$

Where, $\mathrm{F}$ is actual retention after runoff begins, $\mathrm{P}$ is rainfall $(P \geq Q), Q$ is direct runoff, $I_{a}=$ initial abstraction and $S$ is Potential maximum retention after runoff begins $(S \geq F)[16]$.

The Arc Map 10.2 GIS tool was employed to develop the theissen map, soil map and the land use map of the basin. The input to GIS tool was LISS III image and the soil sheet published by ICAR, Nagpur.

These soil and land use maps were the base for determining the composite curve number for the bina basin. The above formulae were then applied in the programmed excel sheet so as to get the estimated direct runoff by the SCS CN method.

\section{AWBM model}

AWBM stands for Australian Water Balance Model. This model is a conceptual, lumped rainfall-runoff model. The basic data required for the setup of AWBM model is listed below:

- $\quad$ Area of catchment in $\mathrm{km}^{2}$

- Rainfall data daily time series in .dat format, $\mathrm{mm} /$ day

- Potential Evapotranspiration data daily time series in dat format, mm/day

\section{Results and Discussions}

Table 1: Theissen weights of rain gauge stations.

\begin{tabular}{|c|c|c|c|}
\hline S.No & Rainfall Station & Percentage Weight (\%) of Station & Individual Weights \\
\hline 1 & Begumganj & 67 & 0.67 \\
\hline 2 & Gairatganj & 22 & 0.22 \\
\hline 3 & Rahatgarh & 9 & 0.09 \\
\hline 4 & Jaisnagar & 2 & 0.02 \\
\hline
\end{tabular}

- Observed data daily time series in .dat format, $\mathrm{mm} /$ day or $\mathrm{m}^{3} / \mathrm{s}$.

The water balance equation employed in this model is given below:

$$
\text { Store }_{\mathrm{n}}=\text { Store }_{\mathrm{n}}+\text { rain }- \text { evap }
$$

Here $n$ value varies from 1to 3. If evapotranspiration is greater than the moisture content, then value becomes negative and the value is set to zero. If moisture in the store becomes greater than its capacity, then runoff is generated. When runoff occurs from any store, part of the runoff becomes recharge of the base flow store. The fraction of the runoff used to recharge the base flow store is BFI * runoff. BFI is the base flow index which is the ratio of base flow to total flow in the stream flow. The remains of the runoff, i.e. (1.0 BFI) * runoff, becomes the surface runoff. The base flow store runs down at the rate of $(1.0-\mathrm{K}) * \mathrm{BS}$, where BS is the current moisture in the base flow store and $\mathrm{K}$ is the base flow recession constant. The surface store operates in the similar way as the base flow store and runs down at the rate of $(1.0-\mathrm{KS}) * \mathrm{SS}$, where SS is the current moisture in the surface runoff store and KS is the surface runoff recession constant.

\section{Model evaluation}

Coefficient of Determination, $\mathbf{r}^{2}$ : The squared value of the coefficient of correlation is termed as coefficient of determination. Mathematically it is expressed as follows:

$$
\mathrm{r}^{2}=\left(\frac{\sum_{i=1}^{n}\left(O_{i}-\bar{O}\right)\left(P_{i}-\bar{P}\right)}{\sqrt{\sum_{i=n}^{n}\left(O_{i}-\bar{O}\right)^{2}} \sqrt{\sum_{i=n}^{n}\left(P_{i}-\bar{P}\right)^{2}}}\right)^{2}
$$

Where, $O$ and $P$ are observed and Predicted values respectively. The range of this evaluation parameter lies between 0 and 1 which describes how much of the observed dispersion is explained by the prediction.

Nash Sutcliffe criteria, E: The efficiency E or $\eta$ was proposed by Nash and Sutcliffe in the year 1970. It is defined as 'one minus the sum of the absolute squared differences between the calculated and observed values normalized by the variance of the observed values' during the period of study.

Mathematically the formula is expressed as:

$$
\mathrm{E}=1-\frac{\sum_{1}^{n}\left(O_{i}-P_{i}\right)^{2}}{\sum_{1}^{n}\left(O_{i}-\bar{O}\right)^{2}}
$$




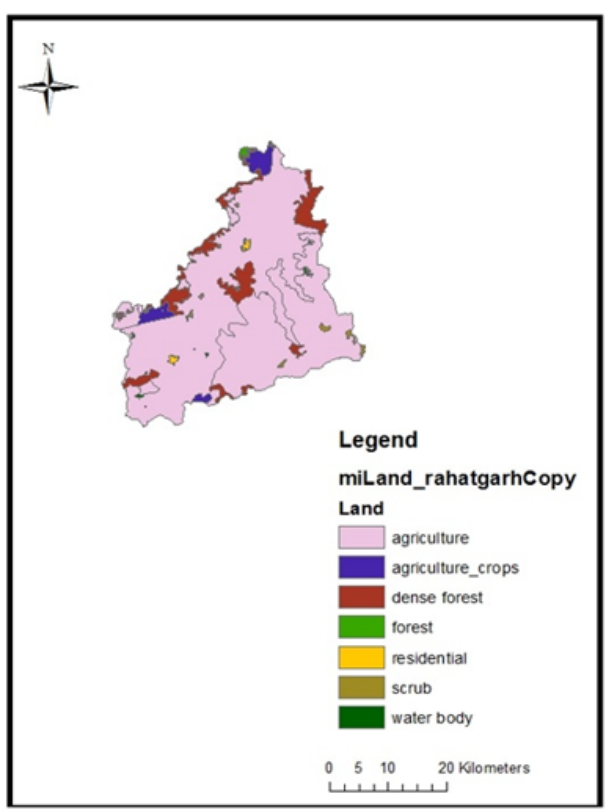

Figure 3: Land Use/ Cover Map.

Using the attributes of the soil map and the land use/cover maps, the maps were merged and layered together so as to derive the composite curve number. The $\mathrm{CCN}$ was found out to be 77 for the bina basin.

- Discharge graphs and Scatter plots of SCS CN model for the period 1990-92 \& 1993-94.
- Discharge graphs and Scatter plots of AWBM model for the period 1990-92 \& 1993-94.

- $\quad$ Comparative bar charts of AWBM RRL, SCS CN and Observed discharge.
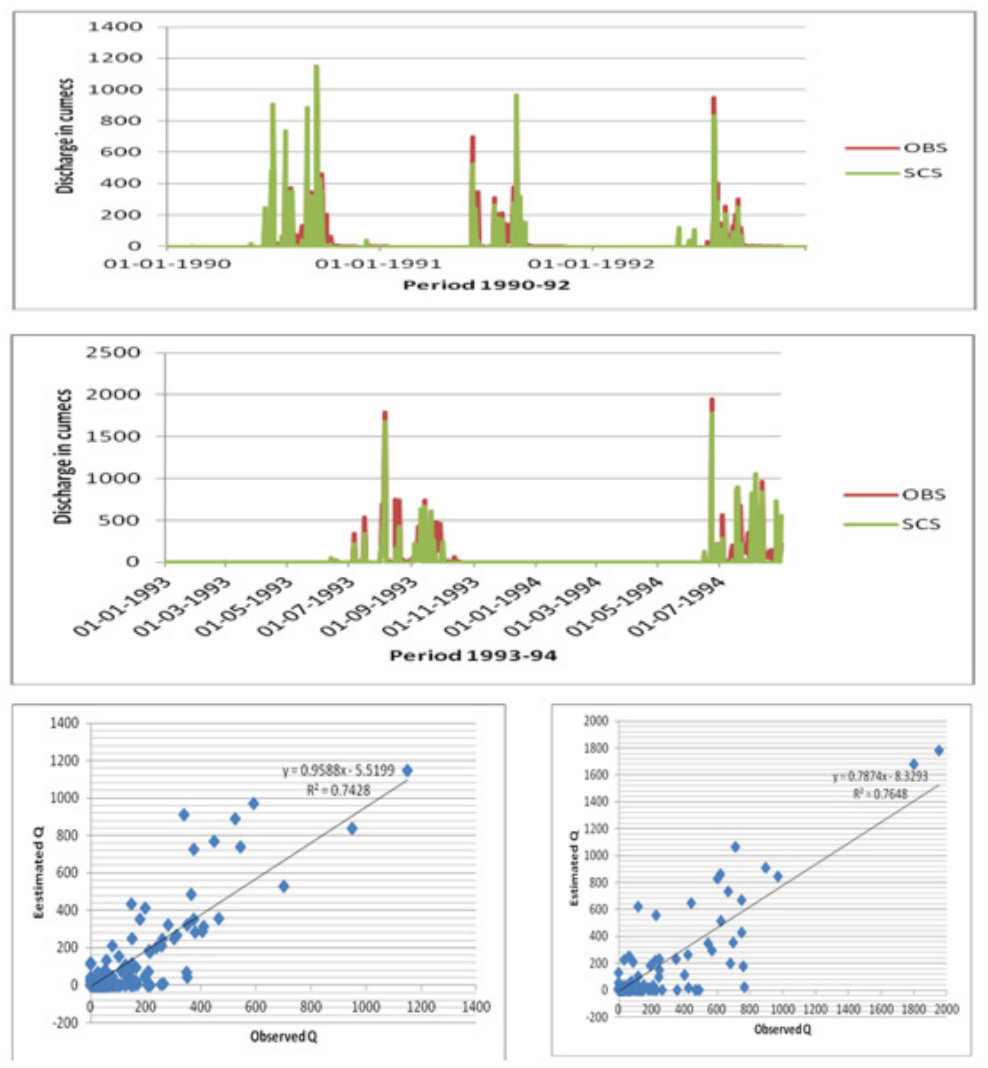

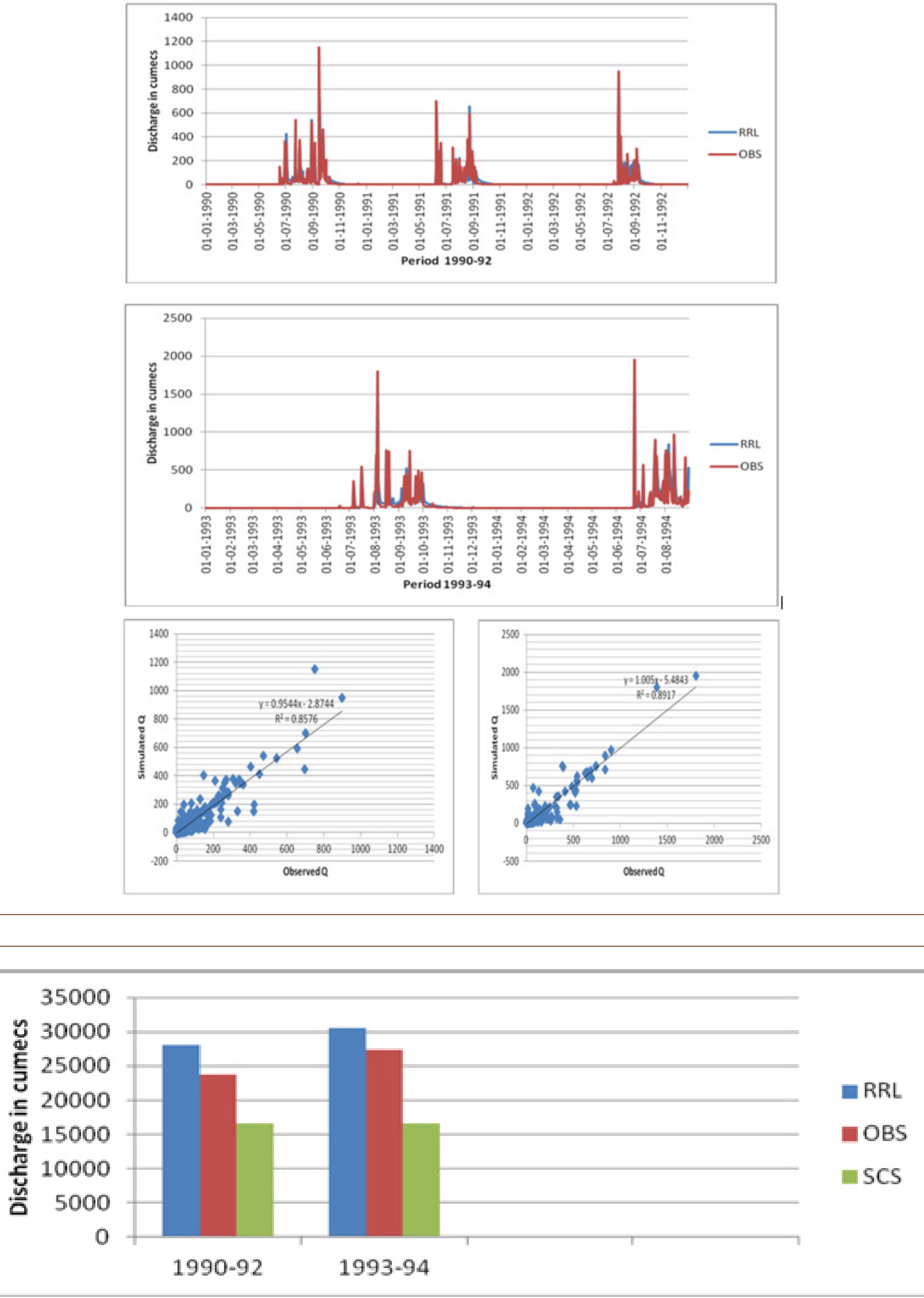
The SCS CN model gave the NSE during 1990-92 as 0.673 and 0.752 for the years 1993-94. The coefficient of determination values was 0.742 and 0.764 for the respective periods. The AWBM RRL model gave the NSE during $1990-92$ as 0.852 and 0.890 for the years 1993-94. Clearly it can be seen that the AWBM RRL model slightly over predicts the discharge and the SCS CN under-predicts. The AWBM also shows good match between the simulated and observed discharge.

\section{Conclusion}

The coefficient of determination values was 0.857 and 0.891 for the respective periods. Between the two applied models, AWBM is found to be more accurate and less time consuming in comparison with the SCS CN model. As the bina project is about to come so the AWBM model can be employed further in the bina basin for prediction of runoff and to get better understanding of the catchment.

\section{Acknowledgement}

None.

\section{Conflict of Interest}

No conflict of interest.

\section{References}

1. Reddy MA (1994) Effect of Land-Use on Transportation Network, A Remote Sensing and GIS Based Techniques Proceedings of International Conference on Remote Sensing and GIS (ICORG 94). Jawaharlal Nehru Technical University, Hyderabad, India.

2. Yu B (1998) Theoretical Justification of SCS Method for Runoff Estimation. Journal of Irrigation and Drainage Engineering 124(6): 306310.

3. Mishra SK, Singh VP (1999) Another Look At SCS-CN Method. Journal of Hydrologic Engineering 4(3): 257-64.

4. Nagarajan N, Poongothai S, Arutchelvan V (2013) Impact of Land Use/Land Cover changes on Surface Runoff from a Rural Watershed. Tamilnadu, India International Journal of Water 7(1/2): 122-41.
5. Boughton W (2006) Calibration of Daily Rainfall Runoff Model with Poor Quality Data Environmental Modeling and Software. Elsevier 21(8): 1114-28.

6. Mahmudul Haque Md, Rahman A, Hagare D, Kibria G (2015) Parameter Uncertainty of the AWBM Model when Applied to an Ungauged Catchment. Hydrological Processes 29(6): 1493-1504.

7. Yu B (2015) How would peak rainfall intensity affect runoff predictions using conceptual water balance models? International Association of Hydrological Sciences 371: 109-115.

8. Balvanshi A, Tiwari HL (2015) Rainfall Runoff Estimation Using RRL Toolkit. International Journal of Engineering Research \& Technology 4(5): 595-99.

9. Pradhan R, Pradhan MP, Ghose MK, Agrawal VS, Agarwal S (2010) Estimation of Rainfall Runoff using Remote Sensing and GIS in and around Singtam. East Sikkim International Journal of Geomatics and Geosciences 1(3): 466-76.

10. Somashekar RK, Ravikumar P, Sowmya SV, Dar MA, Ravikumar AS (2011) Runoff Estimation and Morphometric Analysis for Hesaraghatta Watershed Using IRS-ID LISS III FCC Satellite. Data Journal of Indian Society of Remote Sensing 39(1): 95-106.

11. Latha M, Rajendran M, Murugappan A (2012) Comparison of GIS based SCS-CN and Strange Table Method of Rainfall-Runoff Models for Veeranam Tank. Tamil Nadu India, International Journal of Scientific \& Engineering Research 3(10): 1-5.

12. Dhawale A (2013) Runoff Estimation for Darewadi Watershed using RS and GIS International. Journal of Recent Technology and Engineering 1(6): 46-50.

13. Sundar kumar P, Hanuma Rishi K (2013) Simulation of Rainfall Runoff using SCS \& RRL (Case Study Tadepalli Mandal). International Journal of Engineering Research and General Science 1(1): 23-33.

14.Viji R, Rajesh P, Ilangovan R (2015) GIS based SCS - CN method for Estimating Runoff in Kundahpalam Watershed Nilgries District. Tamilnadu Earth Sciences Research Journal 19(1): 59- 64.

15. Joycee D, Santhi (2015) Assessment of Surface Runoff from Sub Basin of Kodayar using NRCS CN Model with GIS. Indian Journal of Science and Technology 8(13): 1-8.

16. Chow VT (1986) Handbook of Applied Hydrology. McGraw-Hill, New York. 